\title{
Development of composite calcium hydroxide sorbent in mechanical operations and evaluation of its basic sorption properties
}

\author{
Pawet Gara ${ }^{1, *}$, Ewa Wisła-Walsh ${ }^{1}$ \\ ${ }^{1}$ AGH University of Science and Technology, Faculty of Mechanical and Robotics, al. Mickiewicza \\ 30, 30-059 Cracow, Poland
}

\begin{abstract}
This article presents the results of research carried out on the possibility of obtaining composite calcium hydroxide sorbent in the process of two-step granulation, containing additional compounds of $\mathrm{Al}$, $\mathrm{Mg}$ and $\mathrm{Fe}$, and their textural and sorption studies. For this purpose, attempts were undertaken to compact commercial calcium hydroxide powder with six additives in the laboratory roll press. The resulting compacts were crushed and sieved in order to achieve the assumed sieve fraction. Based on the obtained results, basic parameters of the process of formation of composite sorbent have been determined. Both, the selected composite sorbents fractions and additives were subsequently subjected to textural studies (determination of the specific surface area and porosity) and sorption capacity performance. In addition, for the better interpretation of the results, thermogravimetric studies were carried out both for the additives and composite sorbents, as well as the grain size distribution of the additives. The results of the physicochemical tests of the obtained composite sorbents were compared with analogic results from the study on fine-grained hydroxide sorbent without additives and carbonate sorbent. The presented results showed that in a two-step granulation process it is possible to obtain the granular $\mathrm{Ca}(\mathrm{OH})_{2}$ sorbent, as well as composite sorbents possessing better $\mathrm{SO}_{2}$ sorption capacity in comparison to the powder $\mathrm{Ca}(\mathrm{OH})_{2}$ and/or to the calcium carbonate sorbent. This can be attributed to the combination of capability of the sorbent to appropriate thermal decomposition and the formation of a group of pores in the range of 0.07-0.3 microns.
\end{abstract}

\section{Introduction}

Practically since the $1960 \mathrm{~s}$, to reduce emissions of acid pollutants $\left(\mathrm{SO}_{2}, \mathrm{HCl}, \mathrm{HF}\right)$ generated during the combustion of fossil fuels, many methods and technologies are applied in which the sorbent is mainly a high-quality limestone $\left(\mathrm{CaCO}_{3}\right.$ content $\left.>85 \%\right)$ of required grain size [1-3].

The change in the emission limits for sulfur dioxide, expected in the near future, and the obligation to co-fire biomass caused intensification of the search for more efficient sorbents

\footnotetext{
* Corresponding author: pgara@agh.edu.pl
} 
that reduce emissions of $\mathrm{SO}_{2}$ and increase sorption of other acidic pollutants such as $\mathrm{NO}_{\mathrm{x}}$ and $\mathrm{CO}_{2}$ [4-7].

In the fluidized bed boilers, which burn fossil fuels (coal and lignite), the sorbent reducing $\mathrm{SO}_{2}$ emissions is mainly limestone $\left(\mathrm{CaCO}_{3}\right)$ with a high content of calcium carbonate (over $85 \%$ ) $[4,8]$.

Increasing the efficiency of reducing sulfur dioxide emissions from fluidized beds, as in the case of dry methods (FSI, LIMB), is possible first of all by increasing the amount of sorbent introduced to the furnace, or by replacing the calcium carbonate sorbent with a more efficient one, for example the composite hydroxide sorbent [4,7,9-10].

The research conducted so far has shown [10] that, during specific mechanical operations, development of the texture of the obtained material occurs. The BET specific surface area $\left(\mathrm{S}_{\mathrm{BET}}\right)$ of the granular (compacted and crushed) sorbent is more than doubled compared to the value of the parameter for the parent hydroxide in powdery $(<0.09 \mathrm{~mm})$ form. It was also found that the increase in the value of the specific surface area is a consequence of a network of pores with specific diameters and distribution forming during mechanical operations used.

The article presents results of research on the possibility of obtaining a composite hydroxide sorbent in a two-step granulation, containing additives of compounds of aluminum, magnesium and iron, added to increase the specific surface area of the resulting sorbent; the article also presents textural and sorption studies conducted to determine the effects of these additives on the degree of sorption of $\mathrm{SO}_{2}$.

The study consisted in compacting in the LPW450 press powdery calcium hydroxide with six additives (aluminum hydroxide, magnesite, natural goethite, olivine, dolomite waste) and binder (water), the amount of which was determined in previous studies $[10,11]$. The compact obtained in the process of compacting was crushed immediately after production and sieved to separate the granular fraction assumed in the studies.

The separated fractions of composite sorbents and the introduced additives were subjected to tests, which consisted in determining their texture by measuring the specific surface in the raw state, after the thermal decomposition, and after the process of sorption of $\mathrm{SO}_{2}$. Also their sorption capacity with respect to $\mathrm{SO}_{2}$ was established using the $\mathrm{CI}$ index specifying the amount of sulfur dioxide, in grams, adsorbed by $1000 \mathrm{~g}$ of the tested sorbent. $[8,12]$.

For a more accurate interpretation of the results, thermogravimetric tests were carried out for the additives and the obtained composite sorbents, and a study of grain composition of the additives was conducted.

The results of physicochemical tests and sorption capacity tests of the obtained composite sorbents were compared with the corresponding results obtained for the calcium hydroxide sorbent (with no additives) and calcim carbonate sorbent.

\section{The experiment}

Preparation of calcium hydroxide for compacting involved adding an appropriate amount of water (20\% of wt.) and uniformly distributing it in a laboratory Z-type mixer.

Samples of composite sorbents were obtained by preparing calcium hydroxide mixture with additives: aluminum hydroxide in quantities $10 \%$ and $20 \%$, magnesite $10 \%$, natural goethite $10 \%$, olivine $10 \%$ and dolomite waste $10 \%$ of the dry weight of calcium hydroxide. The mixing time was 20-30 minutes, which allowed to obtain homogeneity. The materials were metered into the compaction zone of the laboratory roll press LPW 450 equipped with a gravitational feeder and smooth forming rings.

The compacting process was conducted at a peripheral speed of $0.1 \mathrm{~m} / \mathrm{s}$, while maintaining a $3 \mathrm{~mm}$ gap between the rolls. During the attempts to compact, changes in the 
value of three parameters were recorded: the width of the gap between the forming rolls, the unit pressure, and a torque to the shaft; their sample time characteristics are shown in Figure 1.
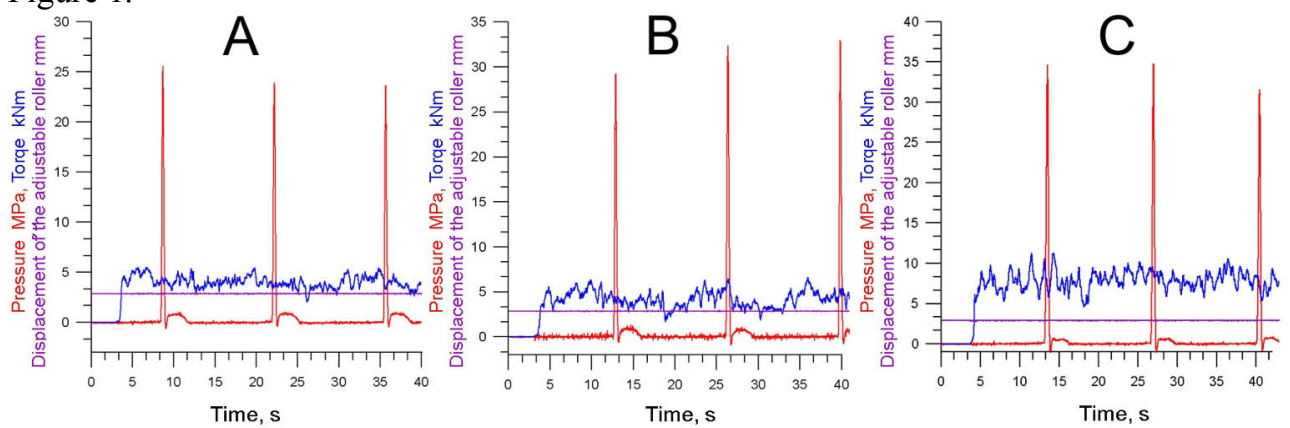

Fig. 1. Time characteristics of the unit pressure and the torque obtained while compacting samples of calcium sorbent (A), a composite sorbent with 10\% (B) and 20\% (C) addition of selected materials.

Immediately after the compaction process the compacts were subjected to crushing and sieving, releasing the assumed fraction. Tests of the crushing process of the compacted material were carried out using a hammer crusher. Independent parameters in the process of crushing were grid spacing value and impact velocity. Based on the results of preliminary research the adopted values were grid spacing of $3 \mathrm{~mm}$ and impact velocity of $8.5 \mathrm{~m} / \mathrm{s}$.

For the obtained fractions of $0.125-0.250 \mathrm{~mm}$ of the calcium hydroxide sorbent (with no additives), six composite sorbents, and the calcium carbonate sorbent, as well as the additives themselves, a series of tests were conducted. The analysis of the grain-size composition of the parent powdery calcium hydroxide and for the crushed and sieved samples of the additives was conducted using a MasterSizer 2000 (MalvernInstr).

The thermal analysis (TG and DTG) in the range of $25-1000^{\circ} \mathrm{C}$ of the tested powdery calcium hydroxide, calcium hydroxide sorbent (with no additives), and six composite sorbents, as well as of the calcium carbonate sorbent and the samples of additives, was conducted using an apparatus Netzsch STA 449 F3.

Measurement of specific surface areas, $\left(\mathrm{S}_{\mathrm{BET}}\right)$, for both parent (untreated) sorbent samples, samples after the thermal decomposition at $850^{\circ} \mathrm{C}$, and samples after the sorption of sulfur dioxide was conducted with the use of Nova 1200 (QuantachromeInst).

The total pore volume, $\left(\mathrm{V}_{\mathrm{CAL}}\right)$ together with their distribution as a function of the diameter of sorbent samples after thermal decomposition, was determined using Poremaster 60 (Quantachrome Inst).

The $\mathrm{SO}_{2}$ sorption index $(\mathrm{CI})$ for the additives decomposed at $850^{\circ} \mathrm{C}$, for the calcium hydroxide sorbent (no additives), six composite sorbents, and calcium carbonate sorbent, was determined, using laboratory equipment. The material for these tests was a fraction of the sorbent, with a grain size in the range of $0.125-0.250 \mathrm{~mm}$ and weight of $1.5 \mathrm{~g}$. After calcination at $850^{\circ} \mathrm{C}$ for half an hour, the samples were contacted at this temperature $\left(850^{\circ} \mathrm{C}\right)$ with gas containing $1780 \mathrm{ppm} \mathrm{SO}_{2}, 3 \% \mathrm{O}_{2}$ and $16 \% \mathrm{CO}_{2}$. On the basis of the obtained results, the $\mathrm{SO}_{2}$ sorption index, CI, was calculated, specifying the amount of sulfur dioxide, in grams, adsorbed by $1000 \mathrm{~g}$ of the tested sorbent.

\section{Results and discussion}

The particle size of the parent calcium hydroxide and additives selected for the study are gathered in Table 1. The presented data show that the tested additives have a similar grain size distribution in relation to the starting calcium hydroxide, with the sample of dolomite 
characterized by the smallest grain size distribution, and with goethite (Ge) having the largest grain size distribution which is very well illustrated by the values of parameters $\mathrm{S}_{\mathrm{CUM}}$ calculated for them, amounting to $1.94 \mathrm{~m}^{2} / \mathrm{g}$ and $0.71 \mathrm{~m}^{2} / \mathrm{g}$, respectively.

Table 1. Grain size distribution - statistical parameters of additives along with their symbols.

\begin{tabular}{|c|c|c|c|c|c|c|}
\hline $\begin{array}{l}\text { Sample } \\
\text { Parameter }\end{array}$ & $\begin{array}{c}\mathrm{Tpp} \\
\mathrm{Ca}(\mathrm{OH})_{2}\end{array}$ & $\begin{array}{c}\mathrm{Al} \\
\mathrm{Al}(\mathrm{OH})_{3}\end{array}$ & $\begin{array}{c}\mathrm{Br} \\
\mathrm{MgCO}_{3}\end{array}$ & $\begin{array}{c}\mathrm{Ge} \\
\mathrm{FeOFe}_{2} \mathrm{O}_{3}\end{array}$ & $\begin{array}{c}\mathrm{Ol} \\
\mathrm{Mg}, \mathrm{FeSiO}_{4}\end{array}$ & $\begin{array}{c}\dot{\mathrm{Ze}} \\
\mathrm{Ca}, \mathrm{MgCO}_{3}\end{array}$ \\
\hline $\begin{array}{c}\text { Mediana-D } 50 \\
{[\mu \mathrm{m}]}\end{array}$ & 12.94 & 22.47 & 15.94 & 35.45 & 8.17 & 6.72 \\
\hline $\begin{array}{c}\text { Mode } \\
{[\mu \mathrm{m}]}\end{array}$ & 26.13 & 25.27 & 34.11 & 48.18 & 14.57 & 11.79 \\
\hline $\begin{array}{c}\mathrm{D}_{10} \\
{[\mu \mathrm{m}]}\end{array}$ & 3.50 & 4.29 & 2.04 & 4.50 & 2.00 & 1.08 \\
\hline $\begin{array}{c}\mathrm{D}_{90} \\
{[\mu \mathrm{m}]}\end{array}$ & 69.58 & 50.50 & 92.99 & 92.75 & 35.74 & 29.99 \\
\hline $\begin{array}{l}\mathrm{S}_{\text {CUM }} \\
{\left[\mathrm{m}^{2} / \mathrm{g}\right]}\end{array}$ & 1.05 & 0.75 & 1.12 & 0.71 & 1.36 & 1.94 \\
\hline
\end{tabular}

Mediana- $\mathrm{D}_{50}$ - The equivalent diameter of particle which has $50 \%$ of the grains found in the distribution (middle value)

Mode - The equivalent diameter of particle most commonly found in the distribution (value that occurs most often)

$\mathrm{S}_{\mathrm{CUM}}$ - Cumulative surface area

In turn, comparing particle size distribution of calcium hydroxide (Tpp) with the particle size distribution of aluminum hydroxide (Al), the impact of the mode on this parameter can be noticed. $\mathrm{S}_{\mathrm{CUM}}$ for aluminum hydroxide is lower by $28.57 \%$ than the value of this parameter for the calcium hydroxide, with almost comparable values of other statistical parameters of grain size distribution.

Table 2 shows the weight losses on heating of additives samples and starting calcium hydroxide, obtained from TG curves.

Table 2. Weight losses during the heating of the samples of starting calcium hydroxide and additives (TG curve).

\begin{tabular}{|c|c|c|c|c|c|c|}
\hline Sample & $\begin{array}{c}\mathrm{Tpp} \\
\mathrm{Ca}(\mathrm{OH})_{2}\end{array}$ & $\begin{array}{c}\mathrm{Al} \\
\mathrm{Al}(\mathrm{OH})_{3}\end{array}$ & $\begin{array}{c}\mathrm{Br} \\
\mathrm{MgCO}_{3} \\
\end{array}$ & $\begin{array}{c}\mathrm{Ge} \\
\mathrm{FeOFe}_{2} \mathrm{O}_{3}\end{array}$ & $\begin{array}{c}\mathrm{Ol} \\
\mathrm{Mg}, \mathrm{FeSiO}_{4}\end{array}$ & $\begin{array}{c}\dot{\mathrm{Z}} \\
\mathrm{Ca}, \mathrm{MgCO}_{3}\end{array}$ \\
\hline \multicolumn{7}{|c|}{$\begin{array}{c}\mathrm{TG} \\
\text { Weight loss [\%] }\end{array}$} \\
\hline $\begin{array}{c}\text { Range } \\
25-130^{\circ} \mathrm{C}\end{array}$ & 0.41 & 0.04 & 0.09 & 3.2 & 0.2 & 0.05 \\
\hline $\begin{array}{c}\text { Range } \\
25-600^{\circ} \mathrm{C}\end{array}$ & 19.9 & 33.6 & 10.11 & 32.6 & 1.7 & 1.91 \\
\hline $\begin{array}{c}\text { Range } \\
25-850^{\circ} \mathrm{C}\end{array}$ & 26.2 & 34.5 & 43.73 & 37.8 & 2.7 & 30.26 \\
\hline
\end{tabular}

Tabulated data shown in Table 2 lead to the conclusion that heating the tested samples of additives up to $110^{\circ} \mathrm{C}$ is accompanied by a gradual, monotonic decrease in mass as a result of release of the physically bound water, while during heating up to about $500^{\circ} \mathrm{C}$ the loss is associated with the dehydroxylation of hydroxides. After exceeding this temperature, the process of decarbonisation of dolomites and carbonates begins. Similarly, Table 3 shows the weight loss on heating for the composite sorbents based on powder calcium hydroxide and for calcium carbonate sorbent (WT). The presented results of thermogravimetric (TG) tests for the obtained composite sorbents and compacted sorbent 
are similar to each other except for the data for the calcium carbonate sorbent. Weight loss at $850^{\circ} \mathrm{C}$ in the case of this sorbent is more than $43 \%$, which is characteristic of calcium carbonates.

Table 3. Weight losses on heating for the composite sorbents sample, and for the calcium carbonate sorbent (TG), together with their symbols.

\begin{tabular}{|c|c|c|c|c|c|c|c|c|c|}
\hline Sample & WT & Tp & TAl & TAl 20 & TBr & TGe & TOl & TŻe \\
\hline \multicolumn{7}{|c|}{$\begin{array}{c}\text { TG } \\
\text { Weight loss [\%] }\end{array}$} \\
\hline $\begin{array}{c}\text { Range } \\
25-130^{\circ} \mathrm{C}\end{array}$ & 0.01 & 0.15 & 0.72 & 2.86 & 0.06 & 0.35 & 0.23 & 0.09 \\
\hline $\begin{array}{c}\text { Range } \\
25-600^{\circ} \mathrm{C}\end{array}$ & 0.36 & 19.97 & 21.63 & 25.31 & 19.85 & 18.40 & 18.65 & 18.40 \\
\hline $\begin{array}{c}\text { Range } \\
25-850^{\circ} \mathrm{C}\end{array}$ & 43.88 & 26.16 & 25.91 & 28.04 & 26.32 & 25.41 & 23.67 & 24.68 \\
\hline
\end{tabular}

All other sorbents are characterized by losses in mass in the range of $23-28 \%$, which corresponds to the percentage of water formed during the dehydroxylation of the calcium hydroxide.

Table 4 shows specific surface values, $\left(\mathrm{S}_{\mathrm{BET}}\right)$ for the starting calcium hydroxide and additives samples used to prepare the composite sorbents.

The specific surface areas were determined for thermally unmodified samples ( $\left.\mathrm{S}_{\mathrm{BET}} \mathrm{NR}\right)$ and, in the case of the additives, also after thermal tretment at $850^{\circ} \mathrm{C}$ for half an hour $\left(\mathrm{S}_{\mathrm{BET} \_\mathrm{R}}\right)$. For comparison, Table 4 also provides the $\mathrm{S}_{\mathrm{CUM}}$ values, determined in the grain size analysis shown in Table 1.

Table 4. The values of specific surface areas $\left(\mathrm{S}_{\mathrm{BET}}\right)$ and geometric surface $\left(\mathrm{S}_{\mathrm{CUM}}\right)$ for the parent materials.

\begin{tabular}{|c|c|c|c|c|c|c|}
\hline $\begin{array}{c}\text { Sample } \\
\text { Parameter }\end{array}$ & $\begin{array}{c}\mathrm{Tpp} \\
\mathrm{Ca}(\mathrm{OH})_{2}\end{array}$ & $\begin{array}{c}\mathrm{Al} \\
\mathrm{Al}(\mathrm{OH})_{3}\end{array}$ & $\begin{array}{c}\mathrm{Br} \\
\mathrm{MgCO}_{3}\end{array}$ & $\begin{array}{c}\mathrm{Ge} \\
\mathrm{FeOFe}_{2} \mathrm{O}_{3}\end{array}$ & $\begin{array}{c}\mathrm{Ol} \\
\mathrm{Mg}_{2}, \mathrm{FeSiO}_{4}\end{array}$ & $\begin{array}{c}\mathrm{Z} \mathrm{e} \\
\mathrm{Ca}, \mathrm{MgCO}_{3}\end{array}$ \\
\hline $\begin{array}{c}\mathrm{S}_{\mathrm{BET}}[\mathrm{NR} \\
{\left[\mathrm{m}^{2} / \mathrm{g}\right]}\end{array}$ & 15.06 & $<0.1$ & 12.90 & 69.9 & 7.5 & 4.64 \\
\hline $\begin{array}{c}\mathrm{S}_{\mathrm{BET}} \mathrm{R} \\
{\left[\mathrm{m}^{2} / \mathrm{g}\right]}\end{array}$ & $(-)$ & 92.2 & 21.97 & 14.0 & 1.9 & 16.08 \\
\hline $\begin{array}{c}\mathrm{S}_{\mathrm{BET}} \mathrm{RS} \\
{\left[\mathrm{m}^{2} / \mathrm{g}\right]}\end{array}$ & $(-)$ & $(-)$ & 8.65 & $(-)$ & $(-)$ & $(-)$ \\
\hline $\begin{array}{c}\mathrm{S}_{\mathrm{CUM}} \\
{\left[\mathrm{m}^{2} / \mathrm{g}\right]}\end{array}$ & 1.05 & 0.75 & 1.12 & 0.71 & 1.36 & 1.94 \\
\hline
\end{tabular}

Data presented in Table 4 shows that the selected addives in the raw state have varying values of specific surface areas compared to conventional sorbents derived from limestone with even much lower particle size. The commercial aluminum hydroxide has the lowest specific surface area, with the proviso that the value of the parameter obtained from the measurements of the low-temperature nitrogen adsorption agrees with the value of the geometric surface area of the sample obtained from the granulometric analysis of particle size, indicating that it is practically non-porous. In contrast, all other additives are of primary porosity, with the sample of natural goethite having the most developed porosity.

After the process of thermal decomposition $\left(850^{\circ} \mathrm{C}-0.5 \mathrm{~h}\right)$ the size of the specific surface for calcium hydroxide and goethite decreases, despite the fact that - except for samples of olivine - the process is associated with significant weight losses resulting from dehydration, dehydroxylation and/or decarbonisation, as discussed above. This indicates 
sintering of pores of smaller diameter to form larger pores; in the remaining samples, the specific surface increases to varying degrees, which can be explained by the development of the texture of the decomposition products (calcium, magnesium and aluminum oxides), most likely associated with the formation of a group of small-diameter pores.

The following table (Table 5) puts together the specific surface area values of the examined composite sorbents, the calcium hydroxide sorbent (without additives) and the calcium carbonate sorbent, for undecomposed samples, $\mathrm{S}_{\mathrm{BET} \text { NRR, samples decomposed at }}$ $850^{\circ} \mathrm{C}$ for half an hour, $\mathrm{S}_{\mathrm{BET}} \mathrm{R}$, and samples after sulfur dioxide sorption conducted at the same temperature, also for $0, \overline{5} \mathrm{~h}$ ( $\left.\mathrm{S}_{\mathrm{BET}} \mathrm{RS}\right)$.

Table 5. The values of specific surface ( $\left.\mathrm{S}_{\mathrm{BET}}\right)$ and surface (SPOR_R) of composite sorbents and calcium carbonate sorbent.

\begin{tabular}{|c|c|c|c|c|c|c|c|c|}
\hline $\begin{array}{c}\text { Sample } \\
\text { Parameter }\end{array}$ & WT & Tp & TAl & TAl 20 & TBr & TGe & TOl & TŻe \\
\hline $\begin{array}{c}\text { SBET_NR } \\
{\left[\mathrm{m}^{2} / \mathrm{g}\right]}\end{array}$ & 0.48 & 28.4 & 22.35 & 27.73 & 21.35 & 24.2 & 19.72 & 25.33 \\
\hline $\begin{array}{c}\mathrm{S}_{\mathrm{BET} / R} \\
{\left[\mathrm{~m}^{2} / \mathrm{g}\right]}\end{array}$ & 12.6 & 5.3 & 12.7 & 17.2 & 6.6 & 5.0 & 5.5 & 5.4 \\
\hline $\begin{array}{c}\text { SPOR_R } \\
{\left[\mathrm{m}^{2} / \mathrm{g}\right]}\end{array}$ & 11.04 & 4.6 & 13.1 & 23.5 & 7.5 & 5.9 & 4.0 & 4.2 \\
\hline $\begin{array}{c}\mathrm{S}_{\mathrm{BEE} / R S} \\
{\left[\mathrm{~m}^{2} / \mathrm{g}\right]}\end{array}$ & $(-)$ & 1.9 & 3.5 & 7.3 & 2.8 & 2.1 & 2.0 & 2.1 \\
\hline
\end{tabular}

$\mathrm{S}_{\mathrm{BET} \_N R}$ - Specific surface area values of undecomposed sorbents

$\mathrm{S}_{\mathrm{BET} \_\mathrm{R}}-$ Specific surface area values of thermally treated sorbents, $\left(850^{\circ} \mathrm{C}, 0.5 \mathrm{~h}\right)$

$\mathrm{S}_{\mathrm{BET}} \mathrm{RS}_{-}$- Specific surface area values of of sorbents measured after $\mathrm{SO}_{2}$ sorption

$\mathrm{S}_{\mathrm{POR} \_\mathrm{R}}-$ Cumulative surface area (porosimetry) of thermally treated sorbents

Table 5 also includes accumulated surface area values, SPOR_R, for samples after thermal decomposition; the values designated by mercury porosimetry.

As shown in the Table 5, the value of the surface of undecomposed calcium carbonate sorbent $\left(0.48 \mathrm{~m}^{2} / \mathrm{g}\right)$ is typical of this kind of minerals of this particular grain size $(0.125-0.250 \mathrm{~mm})$, and indicates that it is practically a non-porous mineral.

The specific surface area of compacted calcium hydroxide (Tp) with the same grain size is higher, compared to the value of this parameter measured for calcium carbonate. It is also almost twice higher than the specific surface area of the starting calcium hydroxide, which suggests expansion of the texture of this material during its production [7,10,11].

When the process of calcium hydroxide compaction occurs with the addition of additives in quantities of $10 \%$, then, for samples of composite sorbents in the raw state (not thermally decomposed), a several percent decrease in the specific surface area of the obtained sorbents is observed. The results obtained for the thermally unmodified composite sorbents samples have confirmed the assumption that the grain size composition of the merged mixtures strongly influences the development of texture during the production of composite sorbents based on calcium hydroxide [10,13].

After a $0.5 \mathrm{~h}$ process of thermal decomposition at $850^{\circ} \mathrm{C}$ the specific surface area of the carbonate sorbent increases as a result of its decarbonisation, which leads to the development of grain texture of the forming calcium oxide. On the contrary, in the case of thermal decomposition of compacted hydroxide sorbent, its surface decreases as a result of the ,reorganization" of the pore structure $[10,16]$.

In turn, analyzing the effects of additives on the surface area values for composite sorbents samples, it can be concluded that addition of aluminum hydroxide results in a noticeable increase in this parameter (2.4 times) at the $10 \%$ share. Increasing the amount of aluminum hydroxide additive to $20 \%$ entails a further increase in $\mathrm{S}_{\mathrm{BET}}$ (3.2 times), with the 
proviso that this increase is not proportional. Introducing other additives to the obtained sorbents hardly affects the size of the specific surface area of the obtained composite sorbents.

Table 5 also shows obtained from the mercury porosimetry measurement the values of surface area, $S_{P O R}$ R for the thermally decomposed sorbents, SPOR_R, and after the sorption of sulfur dioxide, $\mathrm{S}_{\mathrm{BET} \text { RS, }}$, respectively.

The presented data suggest that, for the measurement of the specific surface area of decomposed samples, both of the applied measurement methods (low-temperature nitrogen sorption and porosimetry) yield consistent results, and the observed differences are due to different diameter-ranges in the capillary system tested by these methods.

In turn, specific surface values measured after $\mathrm{SO}_{2}$ sorption suggest that the sorption of sulfur dioxide is accompanied by a similar decrease in the value of this parameter $(\sim 50 \%)$ as a result of the formation of chemisorbed calcium sulfate inside the sorbent pores [13-18] with the exception of samples of composite sorbent with added aluminum hydroxide, the process of closing the pores is accompanied by a smaller $(25 \%)$ decrease in the value of the surface area in that case. It is somewhat less pronounced than for the composite hydroxide sorbent, which may indicate a relatively small contribution of these additives to the $\mathrm{SO}_{2}$ - bonding process. In the case of aluminum hydroxide addition, the presented results may indicate that after the $0.5 \mathrm{~h}$-long sorption process a part of the surface is still available; however, as will be shown further in this paper, it does not participate in the process of sorption probably because of too small pore diameters. This is well illustrated in Figure 2, which compares differential curves of pore volume distribution as a function of their diameter, for the calcium hydroxide sorbent without additives before thermal decomposition ( $\mathrm{T}$ P NR), after thermal decomposition ( $\mathrm{T}$ P R), and after $\mathrm{SO}_{2}$ sorption (T P S).

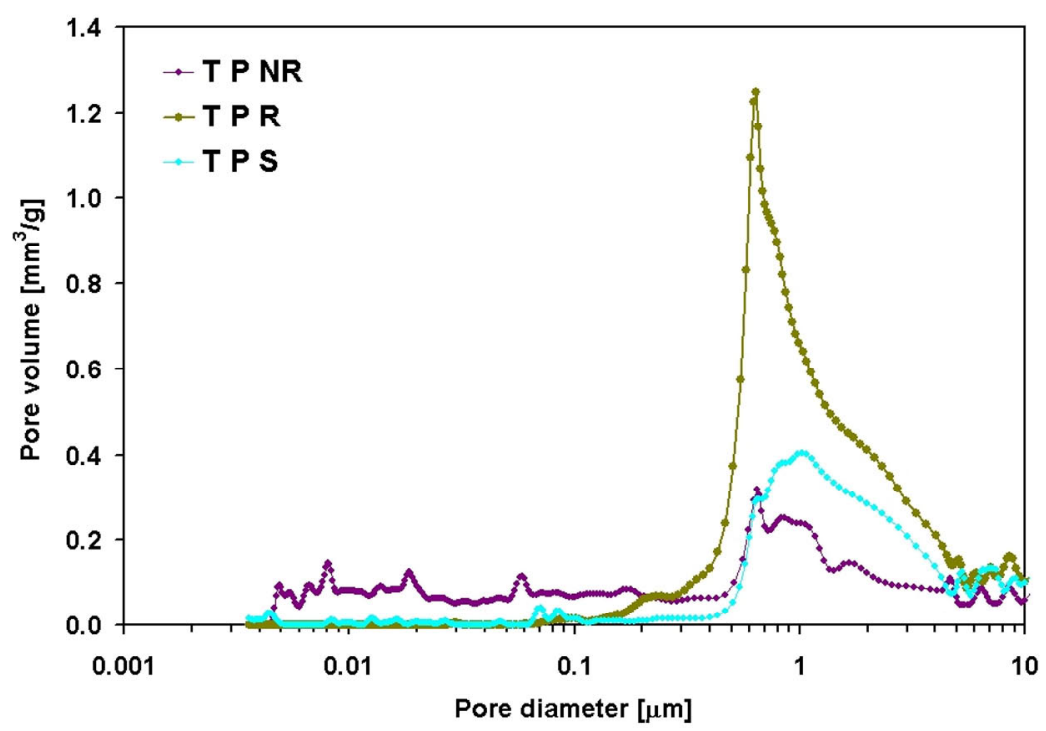

Fig. 2. Differential curves of pore volume distribution for the composite sorbent prior to heating (T P $\mathrm{NR}$ ), after thermal decomposition (T P R), and after $\mathrm{SO}_{2}$ sorption (T P S).

Table 6 compares the values of total pores volume present in the tested composite sorbents and in the calcium carbonate sorbent, obtained for the samples after thermal decomposition together with the mean pore diameter. Figure 3, in turn, presents differential curves of the pore volume distribution as a function of their diameters. 
Table 6. The values of total pore volume $\left(\mathrm{V}_{\mathrm{CAL}}\right)$ and the mean pore diameters Dśr of the composite sorbents and the calcium carbonate sorbent as a function of their diameters.

\begin{tabular}{|c|c|c|c|c|c|c|c|c|}
\hline $\begin{array}{c}\text { Sample } \\
\text { Parameter }\end{array}$ & WT & Tp & TAl & TAl 20 & TBr & TGe & TOl & TŻe \\
\hline $\begin{array}{c}\mathrm{V}_{\mathrm{CAL}} \\
{\left[\mathrm{cm}^{3} / \mathrm{g}\right]}\end{array}$ & 0.575 & 0.768 & 0.622 & 0.585 & 0.668 & 0.625 & 0.483 & 0.600 \\
\hline $\begin{array}{c}\text { DŚR } \\
{[\mu \mathrm{m}]}\end{array}$ & 0.208 & 0.668 & 0.190 & 0.010 & 0.356 & 0.424 & 0.483 & 0.571 \\
\hline
\end{tabular}

$\mathrm{V}_{\mathrm{CAL}}$ - Total pore volume

$\mathrm{D}_{\mathrm{S} R}$ - The mean pore diameters $\mathrm{D}_{\mathrm{S} R}$

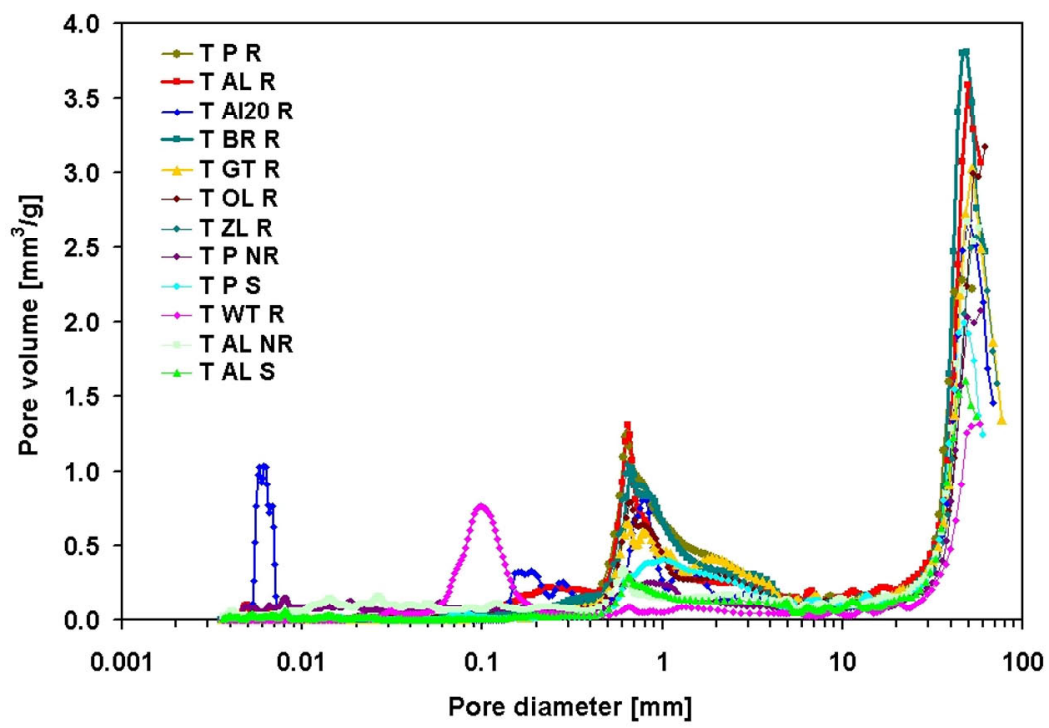

Fig. 3. Differential curves of pore volume distribution as a function of their diameters.

As mentioned above, the data in Table 6 and the differential curves of pore volume distribution as a function of their diameters (Fig.3) for the tested decomposed composite sorbents indicate that there is no correlation between the pore volume and the specific surface area; however, on the example of sample (WT) and (TAl), it can be stated (Fig. 2 and 3) that there is a correlation between the presence of pores with diameters ca. $0.07-0.3 \mu \mathrm{m}$ and this parameter. These correlations and calcium content in the tested samples mutually affect the sorption capacity of these materials, as is shown by test of sorption index CI, results of which are presented in the Tables 7 and 8 below.

Table 7 collects the values of the $\mathrm{SO}_{2}$ sorption index $\mathrm{CI}$, calculated on the basis of measurements carried out in accordance with the above described method.

The values of these parameters obtained for the studied additives, with the exception of the additive $(\dot{\mathrm{Z}} \mathrm{e})$, allow us to conclude that they do not show significant sorption capacity with respect to $\mathrm{SO}_{2}$ (Table 8).

Table 7. Sorption index CI for the tested sorbent additives.

\begin{tabular}{|c|c|c|c|c|c|}
\hline $\begin{array}{c}\text { Sample } \\
\text { Index }\end{array}$ & $\begin{array}{c}\mathrm{Al} \\
\mathrm{Al}(\mathrm{OH})_{3}\end{array}$ & $\begin{array}{c}\mathrm{Br} \\
\mathrm{MgCO}_{3}\end{array}$ & $\begin{array}{c}\mathrm{Ge} \\
\mathrm{FeOFe}_{2} \mathrm{O}_{3}\end{array}$ & $\begin{array}{c}\mathrm{Ol} \\
\mathrm{Mg}_{2} \mathrm{FeSiO}_{4}\end{array}$ & $\begin{array}{c}\dot{\mathrm{Ze}} \\
\mathrm{Ca}, \mathrm{MgCO}_{3}\end{array}$ \\
\hline $\begin{array}{c}\mathrm{CI} \\
{[\mathrm{g} / 1000 \mathrm{~g}]}\end{array}$ & 0 & 17.5 & 10 & 0 & 138 \\
\hline
\end{tabular}


Table 8. Sorption index CI for the tested sorbents.

\begin{tabular}{|c|c|c|c|c|c|c|c|c|}
\hline $\begin{array}{c}\text { Sample } \\
\text { Index }\end{array}$ & WT & Tp & TAl & TAl 20 & TBr & TGe & TOl & TŻe \\
\hline $\begin{array}{c}\text { CI } \\
{[\mathrm{g} / 1000 \mathrm{~g}]}\end{array}$ & 160 & 181 & 229 & 236 & 130 & 157 & 126 & 150 \\
\hline
\end{tabular}

The values of the CI index for the tested sorbents, which are presented in Table 7 and 8 , allow us to conclude that both the calcium carbonate sorbent (WT) and calcium hydroxide sorbent (Tp) (no additives) can be assessed as ,excellent” $[7,8,11]$ in accordance with the currently accepted criterion; however, it must be noted that, in the conditions tested, the hydroxide sorbent is characterized by higher (by $11 \%$ ) reactivity in comparison to the carbonate sorbent (WT).

Introduction of $10-20 \%$ of added aluminum hydroxide causes the CI index obtained for the composite aluminum hydroxide sorbents to increase by about $30 \%$ compared to the parent (no additives) calcim hydroxide sorbent.

Other additives allow obtaining composite sorbents that, according to the above mentioned criteria, can be evaluated as ,good” and „very good” sorbents.

\section{Conclusion}

Based on the analysis of the presented results it was found that in a two-step granulation process it is possible to obtain composite sorbents for general flue gas cleaning from fluidized bed boilers with a simultaneous increase in the melting temperature of the inert layers.

Using industrial $\mathrm{Ca}(\mathrm{OH})_{2}$ with better technical characteristics (higher content of $\mathrm{CaO}$, narrower grain size distribution) than calcium hydroxide used in the earlier studies [10], a sorbent with $22.3 \%$ smaller specific surface area was obtained.

In the tested conditions, despite the smaller specific surface area, $\mathrm{SO}_{2}$ sorption capacity of the obtained granular hydroxide sorbent (without additives) is better than the sorption capacity of the calcium carbonate sorbent.

From among the additives introduced to the calcium hydroxide sorbent, only aluminum hydroxide increases the sorption capacity of the composite sorbent in comparison to hydroxide sorbent, yet increasing the amount of added $\mathrm{Al}(\mathrm{OH})_{3}$ from $10 \%$ to $20 \%$ does not result in a proportional increase in the sorption of $\mathrm{SO}_{2}$.

The introduction of additives such as olivine, dolomite, or magnesite reduces the sorption capacity of the tested composite sorbents in comparison to the calcium hydroxide sorbent. However, these additives do not undergo sintering up to $1000^{\circ} \mathrm{C}$, therefore their presence may increase the melting point of the inert layer in the fluidized bed boilers and help decrease chlorine corrosion.

For the evaluation of the tested sorbents on a technical scale, the hydroxide sorbent with no additives and/or the composite sorbent should be prepared on the basis of calcium hydroxide with a broader grain size distribution.

This article has been prepared within the scope of statutory activity, Contract No. 11.11.130.957. 


\section{References}

1. E. Wisla-Walsh, II National Conference on Science and Technology, "Sorbents for flue gas desulfurization", Kamien Slaski, (1997), (In Polish)

2. R.K. Srivastava, W. Jozewicz, Controlling $\mathrm{SO}_{2}$ Emissions: An Analysis of Technologies. EPA/600/SR-00/093, (November 2000)

3. R.K. Srivastava, W. Jozewicz: J. of the Air \& Waste Management Association, 51, (2001)

4. B. Leckner, Prog. Energy Combust. Sci., 24, (1998)

5. Yan Liu, T.M. Bisson, Hongqun Yang, Zhenghe Xu, Fuel Processing Technology, 91, (2010)

6. T.D. Wheelock, L.K. Doraiswamy, K. Constant, Semi-Annual Technical Progress Report, April 1, 1997 - September 30, 1997

7. N. Lysek, E. Wisła-Walsh, J. Małolepszy, Proceeding of the 2nd European Technical Conference on Lime and Limestone Products. Indispensable Chemicals for Environmental Protection, Produced in Environmentally Compatible Processes, 23/24 October, 1996, Koln.

8. A. Szymanek, Limestone as an $\mathrm{SO}_{2}$ sorbent. Part. I-III. Air protection and waste issues No. 1, 4, 6, (2005), (in Polish)

9. P. Maina, Chem Sci Trans, 2, 1 (2013)

10. P. Gara, M. Hryniewicz, E. Wisła-Walsh, Polish Journal of Environmental Studies, 17, 3A, (2008)

11. P. Gara, Research into selection of compaction and grinding parameters of calcium hydroxide aiming at the development of the specific sorbent, $\mathrm{Ph} \mathrm{D}$ thesis, $\mathrm{AGH}$ Kraków, 2005 (in Polish)

12. N. Lysek, Sorbents for flue gas desulfurization. Production and use (Opolwap S.A., Tarnów Opolski 1997)

13. H.G. Shin, H. Kim, Y.N. Kim, H.S. Lee, J. Mater. Sci. Technol., 25, 3 (2009)

14. J. Adanez, F. Garcia-Labiano, V. Fierro, Chemical Engineering Science 55 (2000)

15. E.J. Anthony, D.L. Granatstein, Progress in Energy and Combustion Science, 27, (2001)

16. W. Jozewicz, B.K. Gullet, Zement-Kalk-Gips, 47, 1 (1994)

17. R.H. Borgwardt, AIChE J, 32, 1986

18. I. Ávila, P.M. Crnkovic, F.E. Milioli, Kai H. Luo, Applied Surface Science, 258 (2012) 